\title{
Experiência da família no manejo da criança com anemia falciforme: implicações para o cuidado
}

\author{
Families' experience in managing children with sickle cell anemia: implications for care \\ Experiencia de la familia en el manejo del niño con anemia falciforme: implicaciones para la atención
}

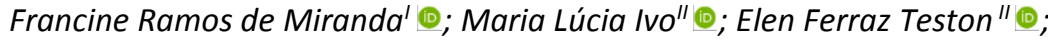

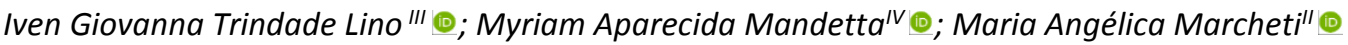

'Faculdade do Mato Grosso do Sul, Campo Grande, MS, Brasil; "Universidade Federal do Mato Grosso do Sul, Campo Grande, MS, Brasil; "'Universidade Estadual de Maringá, Maringá, PR, Brasil;'"Universidade Federal de São Paulo, São Paulo, SP, Brasil

\begin{abstract}
RESUMO
Objetivo: compreender a experiência da família no manejo da criança com anemia falciforme. Método: estudo qualitativo desenvolvido com 14 famílias de crianças com anemia falciforme, mediante entrevistas semiestruturadas abordando o manejo, as experiências e os enfrentamentos vivenciados do diagnóstico ao adoecimento. Utilizou-se como técnica a narrativa e como referencial teórico o Interacionismo Simbólico. Resultados: a experiência da família revela que ela permanece em constante vigilância e proteção, tendo de enfrentar desafios a partir do diagnóstico da anemia falciforme na criança. $\mathrm{O}$ desconhecimento dos profissionais sobre a doença, as lacunas na rede de atenção à saúde e a falta de informação sobre a doença marcam o itinerário, impondo a redefinição na dinâmica familiar. Conclusão: serviços de saúde e profissionais devem ser capacitados para atender as necessidades e demandas da criança com anemia falciforme e de sua família, bem como fornecer informações que as fortaleça.

Descritores: Doença Crônica; Anemia Falciforme; Criança; Família; Enfermagem Pediátrica.
\end{abstract}

\begin{abstract}
Objective: to understand families' experience in managing children with sickle cell anemia. Method: this qualitative study of 14 families of children with sickle cell anemia was conducted by semi-structured interviews addressing the families' management, experiences and coping from diagnosis to illness. The narrative technique was used and Symbolic Interactionism gave the theoretical framework. Results: the families' experiences revealed that they are constantly vigilant and protective, and have to face challenges from the moment their children are diagnosed with sickle cell anemia. Their progress was hindered by health personnel's lack of knowledge about the disease, lacunae in the health care system, and a lack of information about the disease, which imposed a reworking of family dynamics. Conclusion: health services and personnel must be trained to meet the needs and demands of children with sickle cell anemia and their families, and to provide information to strengthen them.

Descriptors: Chronic Disease; Anemia, Sickle Cell; Child; Family; Pediatric Nursing.
\end{abstract}

\section{RESUMEN}

Objetivo: comprender la experiencia de las familias en el manejo de niños con anemia de células falciformes. Método: este estudio cualitativo de 14 familias de niños con anemia falciforme se realizó mediante entrevistas semiestructuradas que abordaron el manejo, las experiencias y el afrontamiento de las familias desde el diagnóstico hasta la enfermedad. Se utilizó la técnica narrativa y el Interaccionismo Simbólico dio el marco teórico. Resultados: las experiencias de las familias revelaron que están constantemente vigilantes y protectoras, y deben enfrentar desafíos desde el momento en que a sus hijos se les diagnostica anemia falciforme. Su avance se vio obstaculizado por el desconocimiento del personal de salud sobre la enfermedad, las lagunas en el sistema de salud y la falta de información sobre la enfermedad, lo que impuso una reelaboración de la dinámica familiar. Conclusión: los servicios y el personal de salud deben estar capacitados para atender las necesidades y demandas de los niños con anemia falciforme y sus familias, y brindar información para fortalecerlos.

Descriptores: Enfermedad Crónica; Anemia de Células falciformes; Niño; Familia; Enfermería Pediátrica.

\section{INTRODUÇÃO}

A anemia falciforme é uma doença genética comum no Brasil que leva às manifestações clínicas como crises álgicas, infecções, desidratações, síndrome torácica aguda, anemia grave, eventos neurológicos e priapismo ${ }^{1}$. A doença exige cuidados mantenedores que permanecem por toda a vida, alternando em períodos de agudização e estabilidade ${ }^{2}$.

Esta doença é considerada uma condição crônica de saúde e, por vezes, em decorrência de complicações, requer adaptações na rotina da criança e de sua família. Isso porque estas vivenciam sentimentos de medo e insegurança diante de um processo desconhecido, o que desencadeia expectativa por informações sobre a condição de saúde da criança e de como se dará o futuro dela ${ }^{1,3}$.

O presente estudo foi realizado com apoio da Coordenação de Aperfeiçoamento de Pessoal de Nível Superior - Brasil (CAPES) - Código de Financiamento 001. Autora correspondente: Iven Giovanna Trindade Lino. E-mail: iven_giovanna@hotmial.com

Editora responsável: Juliana Prata 
Nessa perspectiva, faz-se necessário que os profissionais de saúde sejam sensíveis não apenas às necessidades clínicas, mas também às emocionais, familiares e sociais, bem como estabeleçam um processo educativo para auxiliar a família nas atividades diárias, manutenção da saúde, prevenção e controle das crises, em especial por ser esta uma condição de longo prazo ${ }^{3}$.

Para tanto, os profissionais que atuam na atenção primária ocupam lugar privilegiado para oferecer suporte, em especial, pelo vínculo prévio estabelecido com a família e pelo trabalho desenvolvido no território ${ }^{4}$. No entanto, estudos apontam lacunas nesse processo de cuidado que refletem diretamente no manejo da criança com doença crônica, como por exemplo, a falta de informações sobre a doença, a baixa resolutividade, a dificuldade de acesso, entre outros ${ }^{2,5}$.

Acredita-se que conhecer os desafios das famílias bem como a maneira como elas manejam a situação e lidam com a criança desde o diagnóstico de anemia falciforme pode contribuir para a oferta de cuidados oportunos e para a proposição de intervenções apropriadas. Diante disso, questiona-se: como é o manejo da criança com anemia falciforme pela família?

Para responder ao questionamento norteador, o presente estudo tem como objetivo compreender a experiência da família no manejo da criança com anemia falciforme.

\section{REFERENCIAL TEÓRICO}

O Interacionismo Simbólico (IS) orientou o processo de compreensão da experiência da família e sua relação com a influência da condição crônica de saúde da criança, considerando que esse referencial é uma perspectiva útil para a compreensão da ação humana visto que enfoca o comportamento humano individual e grupal ${ }^{6}$.

Optou-se por esse referencial pois a família está em constante interação simbólica com seus membros, com a equipe de saúde, com a sociedade e com as situações que emergem em seu cotidiano e nos processos interacionais modificados pela condição de doença da criança. Na interação social com o vivido, a família atribui significados que resultam das interações que tem com os elementos presentes na sua experiência com a doença do filho.

\section{MÉTODO}

Estudo descritivo de abordagem qualitativa realizado no ambulatório de hematologia de um hospital público, de grande porte, de um estado da região Centro-Oeste do país. Este serviço recebe uma média diária de 20 crianças, oriundas da capital e das cidades do interior. Por ocasião do estudo, aproximadamente 45 crianças com anemia falciforme estavam em acompanhamento.

Como técnica de pesquisa, utilizou-se a narrativa, que tem o objetivo de extrair, analisar e compreender histórias vividas, exigindo do pesquisador a adoção do pensamento analítico para compreender as narrativas sob as perspectivas holística e integrativa?.

As diretrizes do Consolidated Criteria for Reporting Qualitative Research (COREQ) ${ }^{8}$ nortearam a descrição da metodologia deste estudo. Adotou-se como critério de inclusão, famílias de crianças de um a doze anos, com diagnóstico de anemia falciforme por eletroforese de hemoglobina. A idade inicial foi estabelecida, pois os primeiros sintomas da doença ocorrem, geralmente, aos quatro meses de vida. Dessa maneira, até a criança completar um ano de idade a família já vivenciou várias situações em decorrência da doença. Por sua vez, foram excluídas as famílias que, por ocasião da coleta de dados, se recusaram a participar (duas), não foi possível contato (três) e as demais não compareceram no serviço no período (vinte e seis).

Inicialmente, a pesquisadora principal compareceu no ambulatório, para observação dos atendimentos realizados pela equipe à criança/adolescente, a fim de se aproximar da dinâmica do serviço na assistência às crianças e famílias. Para esta etapa não havia roteiro prévio, no entanto, as percepções referentes ao fluxo do atendimento e comportamento das famílias foram registradas em um diário de campo, que auxiliou na imersão dos dados no momento da análise.

Aproximadamente dois meses após a observação, a pesquisadora principal procedeu a apresentação do estudo e convite à participação das famílias, com o auxílio de um dos profissionais do serviço. Após o aceite, as entrevistas eram agendadas para serem realizadas no ambulatório, antes ou após as consultas e em sala privativa, ou no domicílio da família, de acordo com sua preferência. As famílias participantes foram selecionadas por conveniência, a partir do dia que a pesquisadora principal estava presente no ambulatório.

A coleta de dados ocorreu no período de março a julho de 2016, por meio de entrevistas áudio-gravadas, realizadas pela pesquisadora principal em uma média de 2 encontros com cada família, com duração média de 40 minutos. 
Cada entrevista foi conduzida com o cuidado de permitir às famílias recontarem suas histórias de manejo da criança e contextos impostos pela anemia falciforme. Foi utilizado um roteiro inicial, partindo da solicitação de narrativa ampla da experiência da família no contexto da doença. À medida que a narrativa fluía eram formuladas novas perguntas, visando a descrição da experiência. Exemplos de perguntas que nortearam a entrevista: Como tem sido a trajetória de sua família para manejar os cuidados de saúde a seu filho desde o diagnóstico da anemia falciforme? 0 que tem ajudado e o que tem dificultado o tratamento da anemia falciforme? Como têm sido o atendimento nos serviços que recorrem?

A análise dos dados seguiu o método de pesquisa narrativa, com abordagem das categorias enfatizando o conteúdo ${ }^{7}$. Após as transcrições e as leituras das entrevistas, foram destacados os textos significativos que formaram as categorias.

O estudo obedeceu aos preceitos éticos e foi aprovado pelo Comitê de Ética em Pesquisa com Seres Humanos (CEP), sob o parecer número 1.350.429. Todos os participantes assinaram o Termo de Consentimento Livre e Esclarecido em duas vias, com a identificação adotando o termo "Família", seguido do número da entrevista.

\section{RESULTADOS E DISCUSSÃO}

Foram entrevistadas 14 famílias, tendo como componentes 12 mães, três pais, duas avós, uma tia e uma madrasta. Destas, dez residiam na capital. A idade das crianças variou de dois a 12 anos. Com relação ao grau de escolaridade do familiar entrevistado, três tinham ensino superior, sendo um incompleto, seis com ensino médio completo e cinco com ensino fundamental incompleto. Todas as crianças e adolescentes foram diagnosticadas na ocasião da triagem neonatal.

A experiência das famílias no manejo da criança com anemia falciforme segue descrita a partir do tema representativo A família em constante vigilância e proteção. Frente ao diagnóstico, a família depara-se com o desconhecimento acerca da doença e com o impacto que esse evento provoca em seu cotidiano, uma vez que exige constante cuidado da criança. Diante da falta de informações e das incertezas relacionadas à doença, a família torna-se vigilante e protetora, passando a monitorar a criança e a buscar o que considera ser o melhor para o seu crescimento e desenvolvimento, assim como reorganiza-se para os enfrentamentos necessários. As categorias que dão sustentação ao tema estão descritas a seguir.

\section{Do diagnóstico aos desafios diários}

O diagnóstico da anemia falciforme é impactante para a família, pois não se trata de uma patologia conhecida e divulgada na população, ainda que seja a doença genética mais comum no Brasil. Geralmente a constatação da existência da doença pela família ocorre com as primeiras crises, o agravamento da saúde da criança e a necessidade de hospitalização.

Porque a gente não queria acreditar que ele tinha uma doença. Foi que aí demorou um tempo para a gente entender. Porque a gente via aquele bebezinho saudável. Bonito. Ele não apresentava nada [...] A gente falava "isso aí é mentira, não tem nada". Porque ele não apresentava nada. Não tinha crise no começo. Foi muito difícil da gente acreditar. $O$ dia que eu acreditei mesmo foi o dia que ele teve a primeira crise. Que ele passou muito mal mesmo[...] Ele já internou. Que foi o dia que eu acreditei mesmo que essa doença existia (Família 2).

O desconhecimento inicial da doença impede a família de buscar recursos para se reorganizar. Ao se deparar com os primeiros sintomas da doença, que geralmente são acompanhados pela primeira internação da criança, a família passa a perceber que há algo de grave acontecendo, o que a leva a acreditar que o diagnóstico da doença possa ser verdade. Ao buscar informações, especialmente na internet, a família se depara com imagens e textos que geram incertezas intensificando a angústia pela possibilidade de agravamento da doença.

No começo foi bem difícil. A gente não entendia muito bem da doença[...] A primeira coisa que eu fiz foi ler no Google. Pesquisar. Aí desabou né? Porque lá mostra tudo quanto é coisa de ruim que você imaginar (Família 4).

Frente ao desconhecimento sobre a anemia falciforme e às informações incompreensíveis que recebe, a família busca maneiras de entender a doença em fontes de dados, muitas vezes não confiáveis, gerando maior apreensão.

Receber informações congruentes com as demandas da família contribui para sua compreensão e permite a identificação de situações que possam levar risco à criança. É fundamental que os profissionais de saúde proponham ações de educação em saúde que orientem a família acerca dessa enfermidade e de suas repercussões no organismo da criança. A informação correta tende a evitar complicações e a favorecer a compreensão da família sobre o processo de adoecimento ${ }^{3}$.

Para a família é difícil lidar com as incertezas advindas do diagnóstico, pois desconhecem sua herança genética e só tomam conhecimento da condição de saúde da criança após a realização do teste de triagem neonatal ou em decorrência das primeiras crises na infância. 
Esse fato é um potencial estressor para a família, uma vez que essa condição crônica de saúde irá exigir constantes adaptações nos papéis e na rotina dos membros da família, com vistas ao atendimento das necessidades de cuidado. Estas constatações corroboram com autores de um estudo que reconhecem as repercussões da doença na vida da criança e da família e nas interferências que provocam na dinâmica familiar ${ }^{9}$

Geralmente a mãe assume os cuidados da criança doente. No contexto da anemia falciforme como uma doença crônica, essa situação pode provocar conflitos no relacionamento conjugal, com quebra de vínculos e sobrecarga de cuidados de um de seus membros ${ }^{10}$. A responsabilização de um membro da família pelo evento, somado à falta de conhecimento acerca dele, favorece o rompimento de vínculos familiares:

Para mim é difícil, porque quando descobri que o D. tinha anemia falciforme, o pai dele não quis mais ficar com a gente. Falou que ia embora, porque eu era culpada, tudo veio para cima de mim (Família 9).

A situação de doença crônica reforça o papel de cuidadoras atribuídos às mulheres - mães e avós. Os cuidados das crianças com anemia falciforme frequentemente centralizam-se na figura materna, que, em muitos casos, não recebe apoio, gerando sobrecarga e despontando quadros de ansiedade, depressão e problemas de interação social ${ }^{11}$. Assim, nota-se que as crises da doença perturbam a ordem e a rotina familiar, bem como são fatores de incerteza que abalam o convívio e podem potencializar outros conflitos já existentes na família.

\section{Enfrentamento da família}

O processo de enfrentamento se inicia a partir da constatação da doença e de seu impacto na família, que busca atribuir significados e mobiliza recursos, como a religião e a fé, para o suporte necessário no dia a dia com a criança. 0 sofrimento da criança provocado pelas crises álgicas leva a família a fortalecer o vínculo e a crença espiritual:

Certeza é a fé, é crer em Deus, que é um suporte que nos dá estrutura para caminhar. Porque tem dias, de verdade, que quando você tem uma pessoa com doença crônica na família, você não quer sair da cama, você não quer ver a pessoa que você ama sofrer tanto (Família 13).

É fundamental que a equipe de saúde conheça as crenças religiosas das famílias, permitindo sua assistência espiritual, a qual auxilia no enfrentamento e fortalecimento da resiliência. Há evidências de que a religiosidade e a espiritualidade são componentes inerentes ao enfrentamento de doenças, sendo recursos importantes para os familiares, especialmente diante de prognósticos ameaçadores ${ }^{12}$.

A família destaca que o amor é grande motivador para a busca por melhores condições para a criança, além de ser um fortalecedor da resiliência familiar. A força da criança fortalece a família para seus desafios, ao mesmo tempo em que o medo de perder a criança desencadeia a mobilização de recursos e a luta em prol dela.

Pode parecer besteira, mas é o amor. A gente tem um amor tão grande por ele. Ele é um guri tão especial, que aquilo ali faz com que a gente lute mais. $O$ medo de perder ele é tão grande que a gente briga mais. A gente luta, faz o que pode (Família 14).

Conhecer e passar a conviver com a doença da criança contribuem para um melhor enfrentamento da família. Estar com outros pais que possuem vivências semelhantes auxilia as famílias a trocar experiências e a compartilhar informações que as ajudam no dia a dia e na proteção da criança.

Conhecer outros casos ajudou bastante. Fora isso, [...] é dia-a-dia. Dia após dia, a gente vai aprendendo a conviver. A convivência, no tempo de internação, que eu tive com os outros pais me ajudou (Família 4).

A rede de apoio configurada por outros pais vivendo contextos semelhantes possibilita à família compartilhar experiências e desenvolver vínculos que as fortalece e ajuda. A participação da família em grupos sociais de pessoas com anemia falciforme proporciona a troca de saberes e angústias comuns, promove o fortalecimento e melhora o enfrentamento da situação ${ }^{13}$.

A família sente a necessidade de ser orientada sobre o que está acontecendo com a criança para que possa agir e sentir-se segura no manejo da situação. Ter acesso à informação minimiza a ansiedade da família:

O que ajudaria era ser mais explicado, a gente ter mais informações para gente não ficar ansioso, porque a internet falou isso (Família 3).

É necessário conhecer para enfrentar, cuidar e proteger, saber quais são os sinais e sintomas, o que pode ser feito para prevenir as crises da criança, bem como conhecer como outras famílias manejam situações semelhantes. Neste sentido, a família se torna responsável pela rotina de tratamento, autocuidado e pela percepção que a criança e a própria família têm sobre a condição crônica ${ }^{11}$.

No intuito de proteger a criança e evitar novas crises da doença, a família toma medidas e cuidados de proteção que a impede de ter uma vida comum e de brincar com amigos. Por temer o agravo da doença, afasta a criança dos eventos comuns à infância. 
Elas sempre me pediram muito para tomar banho de chuva, eu nunca deixei, eu sei que elas, de tanto cuidado, se sentiam sufocadas. Porque, eu não deixava comer alimento industrializado, só coisas saudáveis. Não levava em festinha de aniversário para não comer bolo, doces, que eu achava que se eu superprotegesse elas não iam ter crises (Familia 13).

O temor das crises ou agravamento da doença produz excesso de proteção e ressignificação da infância pela família de algo normal para esta fase de vida, tornando-a como algo temeroso e incerto. A superproteção se refere ao modo como os membros da família percebem as fragilidades da saúde da criança. Os sintomas da criança podem potencializar a preocupação da família ${ }^{14}$ de modo que a super protegê-la para a dificuldade da família em resolver situações que a angústia.

No itinerário em busca de informações e atendimento para a criança, as famílias se deparam com a desinformação dos profissionais e com a invisibilidade da doença, manifestados pelo despreparo deles em reconhecer os sinais e sintomas característicos da anemia falciforme, do tratamento e manejo de crises.

Frente à abordagem e ao despreparo profissional no atendimento à criança em crise provocada pela doença, a família precisa, além de tranquilizar a criança, convencer o profissional sobre a gravidade da doença do filho e instruir a conduta que ele deve tomar:

A minha filha gritava de dor quando eu cheguei ao hospital, eu avisei a médica que ela tinha anemia falciforme e que dipirona não ia resolver, mas ela ignorou e minha filha ficou gritando por mais de uma hora (Familia 13).

Os serviços de referência se configuram como um importante apoio para a família, pois são neles que ela obtém algumas das informações necessárias para o cuidado do filho por meio de profissionais capacitados para o atendimento da criança. Entretanto, não encontra socorro em situações de emergência da criança, sobretudo no serviço especializado, visto que o mesmo funciona em nível ambulatorial e através de agendamento de consultas.

Um estudo que discutiu a (in)visibilidade de crianças com necessidades especiais de saúde e suas famílias revelou uma espécie de transferência de responsabilidade pelo cuidado e acompanhamento dessas crianças para as instituições especializadas, o que repercute no desconhecimento das demandas de cuidados deste grupo nos demais serviços de atenção à saúde. Desse modo, a garantia da assistência à essas crianças é um desafio a ser superado pelas famílias, que não têm assegurada a continuidade adequada do seguimento em saúde da criança ${ }^{15}$.

Das 14 famílias entrevistadas, nove não acessam outros serviços que não seja o hospital de referência e o ambulatório especializado, pois sua experiência com outros serviços mostra que os profissionais desconhecem a doença e a conduta terapêutica apropriada, por isso, percebem o despreparo para o manejo das crises de crianças com anemia falciforme:

Eu falei para médica que ela tinha anemia falciforme e a médica me perguntou como ela tinha pego esta doença (Família 13).

Percebido pelas famílias durante o atendimento ao filho, o desconhecimento do profissional de saúde acerca da doença transmite a sensação de invisibilidade da doença e de não validação do que estão vivendo. Cabe salientar que a situação da assistência à saúde prestada à pessoa com doença falciforme é precária, visto que os profissionais de saúde desconhecem as peculiaridades do acompanhamento levando as famílias a não reconhecerem a atenção primária como lugar para cuidar de vários aspectos de sua saúde ${ }^{2}$.

As famílias sentem a necessidade de serem acompanhadas e melhor informadas para a tomada de decisões, inclusive sobre o planejamento familiar futuro.

Quando o médico falou, ele falou, mas não deu uma atenção incisiva de explicar como é [...] Só falou que não poderia mais. Mas, não explicou como era a doença. Porque acho que se tivesse explicado a fundo, a gente não ia esquecer tão fácil, né? Então ele tinha falado para a gente [...] ]evitar, né? Ter um filho. Só que o tempo passou e oito anos depois a gente esqueceu (Família 8).

A narrativa da família reforça a importância de receber informações claras e detalhadas, sobretudo em relação aos riscos. Neste sentido, o Ministério da Saúde aponta que as orientações devem ser transmitidas em linguagem apropriada e com sensibilidade, pois o momento emocional da família pode não favorecer a aceitação e a compreensão imediata dos conteúdos. Além disso, recomenda o aconselhamento genético, com a abordagem dos aspectos hereditários e demais contextos da doença, enquanto um componente essencial da conduta dos profissionais de saúde que assistem a criança com anemia falciforme e sua família ${ }^{16}$.

\section{Limitações do estudo}

Como limitação do estudo, destaca-se a impossibilidade de generalização dos resultados em decorrência da realização em um serviço com características específicas. 


\section{CONCLUSÃO}

Após o diagnóstico, a família da criança com anemia falciforme tem dificuldades para compreender a gravidade da doença e a importância da estabilidade clínica nos primeiros meses de vida. Para o enfrentamento da doença, encontram na fé, nas crenças espirituais e na própria criança a força para prosseguir na busca por melhores condições para sua saúde e crescimento.

Diante dos constantes desafios impostos pela doença, a família maneja e enfrenta a situação como pode, mas, nem sempre, encontra a ajuda necessária ou o apoio dos profissionais de saúde. Nos serviços especializados, os profissionais representam uma importante fonte de informação para a família, porém o acesso a eles é pontual e por ocasião de consultas e exames, o que impossibilita o esclarecimento de dúvidas sobre a anemia falciforme e a saúde da criança. Por isso, torna-se mister que os serviços de saúde e os profissionais sejam capacitados para o atendimento das necessidades e demandas da criança com anemia falciforme e de sua família.

Destaca-se nesse estudo a importância da informação clara e apropriada para qualificar o atendimento de crianças com anemia falciforme e de suas famílias. A escuta atenta, a oferta de tratamento adequado e o fornecimento de orientações sobre a doença e suas implicações na vida da criança e da família são relevantes para uma mudança de paradigma de atendimento a essa população.

\section{REFERÊNCIAS}

1. Souza JM, Rosa PEL, Souza RL, Castro GF. Fisiopatologia da anemia falciforme. Revista Transformar. 2016 [cited 2020 Sep 28]; 8:162-79. Available from: http://www.fsj.edu.br/transformar/index.php/transformar/article/view/60/56.

2. Pacheco DPP, Costa BC, Nascimento LCN, Souza TV, Depianti RB, Laignier MR. Relatives of Children Bearing Sickle Cell Anemia: knowledge and practice. J. res.: fundam. care. online. 2019 [cited 2020 Sep 28]; 11(5):1213-18. DOI: http://dx.doi.org/10.9789/2175-5361.2019.v11i5.1213-1218.

3. Figueiredo SV, Moreira TMM, Clarice SM, Roselene SO, Ilvana LVG. Creation and validation of a health guidance booklet for family members of children with sickle cell disease. Esc Anna Nery Rev. Enferm. 2019 [cited 2020 Sep 28]; 23(1):e20180231 DOI: https://doi.org/10.1590/2177-9465-EAN-2018-0231.

4. Moraes MLS, Zafalon EJ, Bomfim RA, Kodjaoglanian VL, Mendonça de Moraes SH, do Nascimento DDG, et al. Impact of distance education on primary health care indicators in central Brazil: an ecological study with time trend analysis. PLos ONE. 2019 [cited 2020 Sep 28]; 14(3):e0214485. DOI: https://doi.org/10.1371/journal.pone.0214485.

5. Zanello E, Calugi S, Rucci P, Pieri G, Vandini S, Faldella G, Fantini MP. Continuity of care in children with special healthcare needs: a qualitative study of family's perspectives. Ital. j. pediatr. 2015 [cited 2020 Sep 28]; 41(7). DOI: https://doi.org/10.1186/s13052-015-0114-x.

6. Blumer H. Symbolic interacionism: perspect and method. Califórnia: University of California Press; 1986.

7. Bleakley A. Stories as datas, data as stories: making sense of narrative inquiry in clinical education. Med. educ. online. 2005 [cited 2020 Sep 28]; 39(5):534-40. DOI: https://doi.org/10.1111/j.1365-2929.2005.02126.x.

8. Tong A, Sainsbury P, Craig J. Consolidated criteria for reporting qualitative research (COREQ): a 32-item checklist for interviews and focus groups. Int. j.qual. health care. 2007 [cited 2020 Sep 28]; 19(6):349-57. DOI: https://doi.org/10.1093/intqhc/mzm042.

9. Oliveira PP, Gesteira EC, Rodarte AC, Costa MA, Amaral JL, dos Santos WJ. The families assessment children with sickle cell disease. Investig. enferm. 2018 [cited 2020 Sep 28]; 20(2). Available from: http://www.redalyc.org/articulo.oa?id=145256681009.

10. Marcheti MA, Mandetta MA. Intervention with families of children with disabilities based on a theoretical framework developed on vulnerability and resilience model. Rev. Elet. DECT. 2016 [cited 2020 Sep 28]; 6(4). Available from: https://ojs.ifes.edu.br/index.php/dect/article/view/179/173.

11. Lorenci GRF, Paula KMP. Behavioral profile of children with sickle cell anemia. Trends in Psychol. 2015 [cited 2020 Sep 28]; 13(2):269-80. DOI: https://doi.org/10.9788/TP2015.2-03.

12. Araújo AD, Gomes SL, Delmondes G, et al. Children caregiver with cancer: religiosity and spirituality as coping mechanisms. Rev. Cuid. 2016 [cited 2020 Sep 28]; 7(2):1318-24. DOI: http://dx.doi.org/10.15649/cuidarte.v7i2.336.

13. Gesteira ECR, Bousso RS, Rodarte AC. A reflection on family management of the child with sickle cell disease. Rev. enferm. Cent.-Oeste Min. 2016 [cited 2020 Sep 28]; 6(3):2454-62. DOI: https://doi.org/10.19175/recom.v6i3.758.

14. Viana V, Barbosa MC, Guimarães J. Chronic disease in children familiar factors and quality of life. Psicol. saúde doenças. 2007 [cited 2020 Sep 28]; 8(1):117-27. Available from: http://www.scielo.mec.pt/pdf/psd/v8n1/v8n1a09.pdf.

15. Marcon SS, Dias BC, Neves ET, Marcheti MA, Lima RAG. (In)visibility of children with special health needs and their families in primary care. Rev. bras. enferm. 2020 [cited 2020 Sep 28]; 73(4):e20190071. DOI: http://dx.doi.org/10.1590/0034-7167-2019-0071.

16. Ministério da Saúde (Br). Secretaria de Atenção à Saúde. Departamento de Atenção Hospitalar e de Urgência. Doença falciforme: o que se deve saber sobre herança genética Brasília (DF): Ministério da Saúde; 2014. [cited 2020 Sep 28]. Available from: https://bvsms.saude.gov.br/bvs/publicacoes/doenca_falciforme_deve_saber_sobre_heranca.pdf. 